\title{
RICOS E POBRES, CADA QUAL EM SEU LUGAR: a desigualdade socio-espacial na metrópole paulistana
}

\author{
Nelson Baltrusis* \\ Maria Camila Loffredo D'Ottaviano ${ }^{* *}$
}

\begin{abstract}
As favelas e os condomínios fechados expressam a dualidade das formas de morar de ricos e pobres na metrópole paulistana. As ocorrências desses assentamentos acontecem desde a primeira metade do século XX, no caso das favelas, e a partir dos anos 1970, no caso dos condomínios e loteamentos fechados. Este trabalho pretende analisar e identificar tanto os espaços das moradias em condição de extrema vulnerabilidade, particularmente as favelas e unidades habitacionais localizadas em assentamentos periféricos precários, bem como as formas de estruturação do espaço de morar dos ricos e da classe média, destacando, preferencialmente, os condomínios horizontais fechados, como formas de moradia que representam os dois extremos da desigualdade socioterritorial existente no contexto urbano e metropolitano de São Paulo. Trataremos também de refletir sobre as novas formas de apropriação do espaço de morar dos ricos e dos pobres, procurando compreender se existe realmente um novo padrão de ocupação do solo na Região Metropolitana de São Paulo.

PALAVRAS-CHAVE: favelas, condomínios fechados, exclusão socioespacial, RMSP.
\end{abstract}

\section{INTRODUÇÃO}

As favelas e os condomínios fechados vêm sendo usualmente associados à dualidade das formas de morar de pobres e ricos, respectivamente, na metrópole paulistana. As ocorrências desses assentamentos acontecem desde o inicio do século XX, no caso das favelas (desde os anos 1940, no caso das favelas paulistanas), e a partir dos anos 1970, no caso dos condomínios e loteamentos fechados. A segregação socioterritorial tem se dado no contexto das cidades brasileiras historicamente, de várias formas: cortiços, bairros segregados, bairros altos e bairros baixos, etc. Se, de fato, a

\footnotetext{
* Sociólogo. Doutor em Arquitetura e Urbanismo pela Faculdade de Arquitetura e Urbanismo da Universidade de São Paulo. Professor do Mestrado em Planejamento Territorial e Desenvolvimento Social da Universidade Católica do Salvador.

Av. Anita Garibaldi, 2981. Cep: 41940-450. Rio Vermelho - Salvador - Bahia - Brasil.nbaltrusis@hotmail.com

* * Doutora em Arquitetura e Urbanismo pela Faculdade de Arquitetura e Urbanismo da Universidade de São Paulo. Professora do Curso de Arquitetura da Universidade São Francisco (USF) Itatiba. Pesquisadora do Centro de Estudos Urbanos.

Rua: Alexandre Rodrigues Barbosa, 45 - Centro. Cep: 13.250000 - Itatiba - São Paulo-Brasil. camila.dottaviano@gmail.com
}

segregação socioterritorial das cidades brasileiras não é um fenômeno recente, as favelas e os loteamentos e condomínios fechados se consolidam como paradigma da segregação socioespacial brasileira a partir de meados dos anos 1980. Apesar de fenômenos distintos, essas formas de moradia representam dois extremos da desigualdade socioterritorial existente no contexto urbano metropolitano.

Para Mike Davis (2006), as favelas são a expressão mais clara desse novo modelo de desenvolvimento urbano. Para o autor de Planeta Favela, nas cidades pós-modernas do século XXI, ao contrário do que previam os urbanistas, verifica-se que:

... as cidades do futuro, em vez de feitas de vidro e aço, como fora previsto por gerações anteriores de urbanistas, serão construídas em grande parte de tijolo aparente, palha, plástico reciclado, blocos de cimento e restos de madeira. Em vez das cidades de luz arrojando-se aos céus, boa parte do mundo urbano do século XXI instala-se na miséria, cercado de poluição, excremento e deterioração. Na verdade, o bilhão de habitantes que moram nas favelas pós-modernas podem olhar com inveja as ruínas das robustas casas de barro de Çatal Hüyük, na Anatólia, construídas no alvorecer da vida urbana há 9 mil anos (p.29). 
Por outro lado, uma parte da população mais rica se isola da cidade real e constrói seus espaços de moradia em condomínios e loteamentos fechados, renegando a função pública da cidade, fragmentando o espaço urbano e contribuindo para a consolidação da não-cidade. No entanto, o que se observa é que esses espaços atraem novas favelas, que irão abrigar os trabalhadoeres e serviçais dessas fortalezas, criando o fenômeno dual que pode ser descrito como Alphaville-Alfavela. ${ }^{1}$

Este artigo pretende analisar e identificar tanto os espaços das moradias em condição de extrema vulnerabilidade, particularmente as favelas e unidades habitacionais localizadas em assentamentos periféricos precários, bem como as formas de estruturação do espaço de morar dos ricos e da classe média, destacando, preferencialmente, os condomínios horizontais fechados, localizados na metrópole paulistana. ${ }^{2}$

O trabalho se estrutura da seguinte forma: em primeiro lugar, trataremos de contextualizar a Região Metropolitana de São Paulo (RMSP) através da leitura de bibliografia sobre a problemática habitacional e de dados censitários gerais, apoiando-nos em trabalhos de Torres e Marques (2002), Pasternak (2003), Pasternak e Bógus (2003), e Pasternak e Baltrusis (2003) e comparando-os com outras regiões e com os indicadores nacionais. A análise dos indicadores habitacionais nos $39 \mathrm{mu}$ nicípios que compõem a RMSP foi realizada a partir da leitura das informações censitárias e dados municipais e regionais.

Trataremos também de refletir sobre as novas formas de apropriação do espaço de morar dos ricos e dos pobres, com apoio nos trabalhos de Caldeira (2000) e Souza(2000), entre outros, para procurar apreender o processo de estruturação das metrópoles a partir desse novo padrão de ocupação. Nesse sentido, procuraremos compreender se existe realmente um novo padrão de ocupação do solo nas metrópoles. Algumas questões se colo-

${ }^{1}$ Neste trabalho, não abordamos essa dualidade; apenas constatamos a sua incidência em algumas partes da metrópole.

2 Este trabalho foi desenvolvido no âmbito do Observatório das Metrópoles, PUC-SP/FAUUSP. cam. Será que esse novo padrão não seria uma releitura de como os espaços na cidade são apropriados na sociedade brasileira? Se, de fato, essa apropriação for nova, o que a difere das outras formas ainda existentes? Como e por que elas aconteceram nas cidades da Região Metropolitana? Podemos dizer que elas seriam o reflexo de uma nova economia urbana? Enfim, procuraremos levantar algumas questóes críticas sobre essa dualidade.

\section{APOPULAÇÃO FAVELADABRASILEIRA: algumas estimativas}

O aumento do número de favelas e da população favelada no Brasil, nas duas últimas décadas, pode ser sentido em várias cidades, principalmente nas grandes cidades e nas metrópoles. De acordo com Pasternak (2003), as favelas estão

... crescendo a taxas maiores que a população
total: as taxas anuais de crescimento
populacionais entre 1980 e 1991 foram, para a
Brasil, de $1,89 \%$, e para os domicílios favelados,
de $7,65 \%$; na última década do século XX o in-
cremento favelado, de $4,18 \%$ anuais, continuou
maior que o geral, de $1,63 \%$ anuais. O $2^{\circ}$ Milê--
nio terminou com 3.905 favelas espalhadas pelo
país, segundo os dados do IBGE, considerados
subestimados por muitos estudiosos (p.1).

Nesse sentido, Denaldi, citando Bremaeker (2001), destaca que, em 2000, "a totalidade das grandes cidades brasileiras (com mais de $500 \mathrm{mil}$ habitantes) apresenta favelas, assim como cerca de $80 \%$ das cidades com população de 100 e 500 mil habitantes" (Denaldi, 2000).

Tabela 1 - Brasil. Favelas, segundo grandes regióes, 1991 e 2000

\begin{tabular}{l|r|r|r}
\hline \multicolumn{1}{c|}{ Regiáo } & $\mathbf{1 9 9 1}$ & $\mathbf{2 0 0 0}$ & Diferença \\
\hline Norte & 59 & 185 & 126 \\
\hline Nordeste & 517 & 674 & 157 \\
\hline Sudeste & 2.225 & 2.621 & 396 \\
\hline Sul & 327 & 392 & 65 \\
\hline Centro-Oeste & 59 & 34 & -25 \\
\hline Brasil & 3.187 & 3.906 & 719 \\
\hline
\end{tabular}

Fonte: Censo Demográfico de 1991; Sinopse Preliminar do Censo de 2000. In: Pasternak, 2003. 
A maior parte das favelas (67\%) e dos aglomerados favelados do Brasil se concentra na região Sudeste. São Paulo é o Estado que apresentou o maior número de favelas em 2000, com 1.548 favelas, seguido do Rio de Janeiro, com 811 favelas, no período de 1991-2000, 279 a mais que em 1991. Entre 1991 e 2000, surgiram 719 novas favelas. A pressão do déficit de moradias nos grandes centros também se tornou evidente no recenseamento que listou os municípios com maior número de favelas. Entre os municípios brasileiros, São Paulo lidera, com 612 aglomerados, seguindo-se o Rio de Janeiro, com 513. A lista, até o décimo colocado, se completa com Fortaleza (157), Guarulhos (136), Curitiba (122), Campinas (117), Belo Horizonte e Osasco (101 cada), Salvador (99) e Belém (93).

As favelas no Brasil expressam um fenômeno predominantemente metropolitano. Em nove regiões metropolitanas se concentram cerca de $80 \%$ das favelas e domicílios favelados do país. "Em 1991, 2.391 favelas (74\%), de um total de $3.211 \mathrm{e}$ 817.603 (78\%) dos domicílios favelados se alocavam nas metrópoles"(Pasternak, 2003, p.1). Nessas regiões, os municípios-sede apresentam uma concentração maior de população favelada. No município de São Paulo, Pasternak (2003) destaca que "os dados censitários apontam, em 2000, para uma população favelada de cerca de $930 \mathrm{mil}$ pessoas. Entre 1980 e 2000, o crescimento da população favelada foi 11 vezes maior que o crescimento da população total do município" (p.1). Percebe-se um movimento de formação de novas favelas e crescimento das já existentes, localizadas nos bairros periféricos do município-sede e nos municípios periféricos da Região Metropolitana.
O crescimento do número de favelas e da população favelada não pode ser explicado apenas pelo empobrecimento da população urbana brasileira. Ele tem a ver também com a própria forma como o espaço urbano se estrutura em nossas cidades, de forma fragmentada e segmentada, revelando a fragilidade do processo de produção do espaço urbano nas grandes cidades e expondo a vulnerabilidade das favelas na estrutura urbana. O adensamento das favelas mais antigas, localizadas em bairros centrais, bem como o espraiamento das mais recentes, nas áreas da periferia, demonstram que o problema da favela como opção de moradia está longe ser resolvido. Esse tipo de moradia vem ganhando novas faces não só pela diversidade das formas de ocupação e de estruturação das condições habitacionais, mas também de como se relacionam com o seu entorno e com a própria cidade.

O Censo de 2000 confirma que, embora as diferenças entre as taxas de crescimento de domicílios totais e favelados venham se aproximando, podemos verificar que, entre 1980-1991, a taxa geométrica de crescimento para as favelas era de $8,18 \%$, enquanto, para o total de domicílios, era de 3,08\%. Já no período 1991-2000, a taxa de crescimento dos domicílios favelados diminuiu para 4,18\%, aproximando-se mais da taxa de crescimento dos domicílios (3,05\%). Porém a taxa de crescimento dos domicílios favelados ainda é consideravelmente superior que a total.

O crescimento dos domicílios favelados, entre 1980 e 1991, pode ser explicado, de um lado, pela falência do Sistema Financeiro de Habitação, que culminou com a quebra do Banco Nacional de

Tabela 2 - Brasil. Domicílios totais e favelados, por grande região, 1980,1991 e 2000

\begin{tabular}{l|c|c|c|c|c|c}
\hline \multirow{2}{*}{\multicolumn{1}{c}{ Regiáo }} & \multicolumn{3}{|c}{ Domicílios totais } & \multicolumn{3}{c}{ Domicílios favelados } \\
\cline { 2 - 7 } & 1980 & 1991 & 2000 & 1980 & 1991 & 2000 \\
\hline Norte & 1.219 .496 & 2.376 .607 & 3.353 .764 & 12.721 & 97.760 & 178.326 \\
\hline Nordeste & 8.036 .803 & 10.920 .830 & 13.911 .413 & 69.974 & 286.130 & 306.395 \\
\hline Sudeste & 13.761 .346 & 18.839 .621 & 24.699 .909 & 357.330 & 675.846 & 1.038 .608 \\
\hline Sul & 4.826 .030 & 6.598 .962 & 8.509 .284 & 30.077 & 73.325 & 110.411 \\
\hline Centro-Oeste & 1.812 .176 & 2.657 .621 & 3.791 .248 & 10.493 & 11.257 & 16.808 \\
\hline Brasil & 29.657 .831 & 41.395 .632 & 54.267 .618 & 480.595 & 1.141 .324 & 1.650 .548 \\
\hline
\end{tabular}


Tabela 3 - Brasil. Taxas geométricas de crescimento dos domicílios totais e favelados, por grande regiáo

\begin{tabular}{l|c|c|c|c}
\hline \multirow{2}{*}{ Região } & \multicolumn{2}{|c|}{ Domicílios totais } & \multicolumn{2}{c}{$\begin{array}{c}\text { Domicílios } \\
\text { favelados }\end{array}$} \\
\cline { 2 - 5 } & $\begin{array}{c}1980- \\
1991\end{array}$ & $\begin{array}{c}1991- \\
2000\end{array}$ & $\begin{array}{c}1980- \\
1991\end{array}$ & $\begin{array}{c}1991- \\
2000\end{array}$ \\
\hline Norte & 6,25 & 3,90 & 20,37 & 6,91 \\
\hline Nordeste & 2,83 & 2,73 & 13,66 & 0,76 \\
\hline Sudeste & 2,90 & 3,06 & 5,96 & 4,89 \\
\hline Sul & 2,89 & 2,87 & 8,44 & 4,65 \\
\hline Centro-Oeste & 3,54 & 4,03 & 0,64 & 4,55 \\
\hline Brasil & 3,08 & 3,05 & 8,18 & 4,18 \\
\hline Fonte: IBGE. In: Pasternak, 2003. &
\end{tabular}

Habitação na década de 80. E, de outro, pela crise econômica que o país atravessava, que aliou um alto nível de desemprego com a hiperinflação. De acordo com Pasternak, "o salário mínimo perdeu $46 \%$ do seu valor real na década de 80 e a concentração de renda é espantosa" (1997, p. 4).

No período de 1980 a 1991, o Estado não foi capaz de conduzir uma política habitacional que produzisse ou financiasse habitações para a população de baixa e média renda. Esse fator, aliado à reestruturação produtiva das empresas, intensificou o desemprego. O processo inflacionário corroeu os salários dos empregados e contribuiu para o aumento do valor dos aluguéis. A população de baixa renda se viu obrigada a buscar novas opções para morar, entre elas ocupar terras e autoconstruir a sua moradia. O que se viu, nos anos 80, foi um processo de ocupação de terras urbanas (públicas e particulares) por movimentos organizados de luta por moradia que forçaram os governos municipais a se posicionarem. Nesse período, começaram, ainda que de forma embrionária, algumas experiências de regularização fundiária, de urbanização e até de construção de novas unidades pelo poder público local.

O que se percebeu, no período seguinte, entre 1991-2000, foi a proliferação de favelas nas Regiões Metropolitanas, particularmente nas localidades mais afastadas do centro, criando-se, assim, um 'novo padrão de ocupação periférica'. Esse 'padrão' reflete, por um lado, uma nova organização do espaço urbano nos grandes centros, baseada na segregação urbana, que, de acordo com Castells e Mollenkopf (1992), deve ser entendida como uma "tendência à organização do espaço em zonas de forte homogeneidade social interna e de forte disparidade social entre elas, entendendo-se essta disparidade não só em termos de diferença como também de hierarquia"(Castells, apud Villaça 2001, p.148).

No contexto da Região Metropolitana de São Paulo, novas favelas se consolidaram nas áreas periféricas e nas zonas ambientalmente frágeis, como as áreas de proteção de mananciais, fundos de vales e encostas de morros. Paralelamente a isso, as favelas existentes vêm passando por um processo continuado de adensamento.

\section{FAVELASNA RMSP (aglomerados sub-normais)}

Nas últimas três décadas, as favelas se consolidaram como uma alternativa de moradia para a população de baixa renda. De acordo com dados do Censo 2000, sistematizados pela Fundação João Pinheiro para o cálculo do déficit habitacional brasileiro dos 39 municípios da RMSP, apenas 20 deles possuíam favelas. As favelas da RMSP se localizam nas regiões periféricas do município-polo (São Paulo) e nos municípios próximos, formando uma mancha que ocupa áreas ambientalmente frágeis, como as áreas de proteção das represas Billings e Guarapiranga, ao sul e sudeste, e a Serra da Cantareira, ao norte. Já as favelas mais centrais se localizam em geral em locais próximos a potenciais mercados de trabalho (formais ou informais) e próximos às vias expressas e rodovias. Estudos como o de Abramo (2003) e Baltrusis (2000) apontam para a importância, entre outros fatores, da localização do assentamento favelado próxima ao local de trabalho ou com possibilidade de acesso a um sistema de transporte eficiente.

Os dados apontam que 10,08\% do total dos domicílios da RMSP estão localizados em favelas.

\section{O crescimento das favelas na RMSP}

O processo de favelização da Região Metropolitana de São Paulo é um fenômeno recente e 
que se intensificou nos últimos 30 anos. ${ }^{3}$ Podemos classificá-lo como uma expressão do processo desigual de produção social do espaço nas cidades brasileiras. Do ponto de vista territorial, evidencia a desigualdade econômica existente na sociedade brasileira. As favelas, aliadas a outras formas de ocupação, como os loteamentos irregulares e assentamentos precários, demonstram a 'vulnerabilidade socioterritorial's de grande parcela da população.

O crescimento das favelas transforma o desenho do espaço urbano bem com as relações socioterritoriais. Pasternak e Bógus (2003) descrevem a cidade de São Paulo e, por extensão, a sua Região Metropolitana como uma cidade dos anéis: quanto mais periférico for o anel, mais exclusão social e territorial. ${ }^{5}$ De acordo com Pasternak (2003),

... todo o acréscimo populacional aloca-se na periferia. Entre 1996 e 2000, os 3 anéis centrais perderam quase 46 mil pessoas, e os anéis exterior e periférico ganharam mais de 600 mil habitantes. Os moradores mais pobres são impelidos para regiões cada vez mais distantes, tanto para o entorno da capital como para as cidades limítrofes. A polarização social, visível a olho nu, ganha novos contornos: a pobreza se espalha por todo o tecido municipal, enquanto que as classes mais abastadas se concentram em verdadeiros enclaves de riqueza, sobretudo na região sudoeste da capital. As demais camadas sociais se distribuem de forma espraiada, empobrecendo em direção da periferia (p. 4).

Porém Valladares e Pretéceille (2000) alertam que elas não devem ser associadas pura e simplesmente com o "espaço típico de concentração de pobreza urbana”. Essa associação, comum a vários autores e à mídia em geral, não pode nem deve ser considerada uma regra, "uma vez que as favelas não se distinguem assim tão fortemente do conjunto do tecido urbano e que as situações de pobreza urbana extrema são mais frequentes fora das favelas” (p. 399).

\footnotetext{
${ }^{3}$ Até a década de 70 do século XX, a principal forma de informalidade na Região Metropolitana de São Paulo era o loteamento clandestino. A esse respeito existem vários trabalhos: Kowarick (1979), Maricato (1979), Bonduki e Rolnik (1979).

${ }^{4}$ Alguns autores como Kowarick (1979) e Sposati (1996), entre outros, trabalham com o conceito de vulnerabilidade.

${ }^{5}$ Para aprofundar essła definição, ver Pasternak e Bógus (2000).
}

\section{O espaço das favelas na cidade}

Ao observar o Mapa 1 a seguir, que apresenta a localização das favelas na RMSP, percebemos que as favelas se concentram prioritariamente nos municípios periféricos, próximos ao municípiopolo, caminhando em direção aos municípios fronteiriços à RMSP. Em alguns casos, nota-se uma tendência de conurbação das favelas dos municípios do ABCD com os municípios da Região Metropolitana da Baixada Santista. Podemos apreender que esses fluxos formam pelo menos três blocos consolidados de municípios. No primeiro bloco, localizado a Sudeste, encontramos os municípios da subregião ABCD (Santo André, São Bernardo do Campo, Diadema e Mauá), as rodovias Anchieta e Imigrantes que cortam a região estabelecem um eixo de municípios que possuem favelas, extrapolando a Região Metropolitana de São Paulo e se interligando com as periferias dos municípios de Santos e Cubatão, na Região Metropolitana da Baixada Santista. Esse mesmo fenômeno vai acontecer no bloco a Noroeste, com as rodovias Anhanguera e Bandeirantes, que, ao passarem nas proximidades dos municípios de Cajamar, Caieiras, Franco da Rocha e Francisco Morato, estabelecem um eixo de ligação com alguns municípios da Região Metropolitana de Campinas. Nesse segundo bloco, no entanto, aparentemente não existe uma conurbação das favelas dessas duas regiões.

À Oeste, a rodovia Castelo Branco articula os municípios de Osasco, Barueri, Carapicuíba, Santana do Parnaíba e Itapevi, enquanto a rodovia Raposo Tavares conglomera os municípios de Cotia, Embu, Taboão da Serra e Vargem Grande Paulista.

Temos ainda a Leste os municípios de Guarulhos e Itaquaquecetuba, -que não chegam a formar um bloco, mas que são cortados pelas rodovias Presidente Dutra, Ayrton Senna e Fernão Dias. Esses municípios também apresentam uma grande quantidade de favelas e loteamentos irregulares.

Assim, as estradas formam verdadeiros eixos ao longo dos quais se concentram as favelas e os assentamentos ilegais nos municípios periféricos. A possibilidade de deslocamento e as atividades eco- 


\section{Mapa 1 - RMSP Distribuição das Favelas}

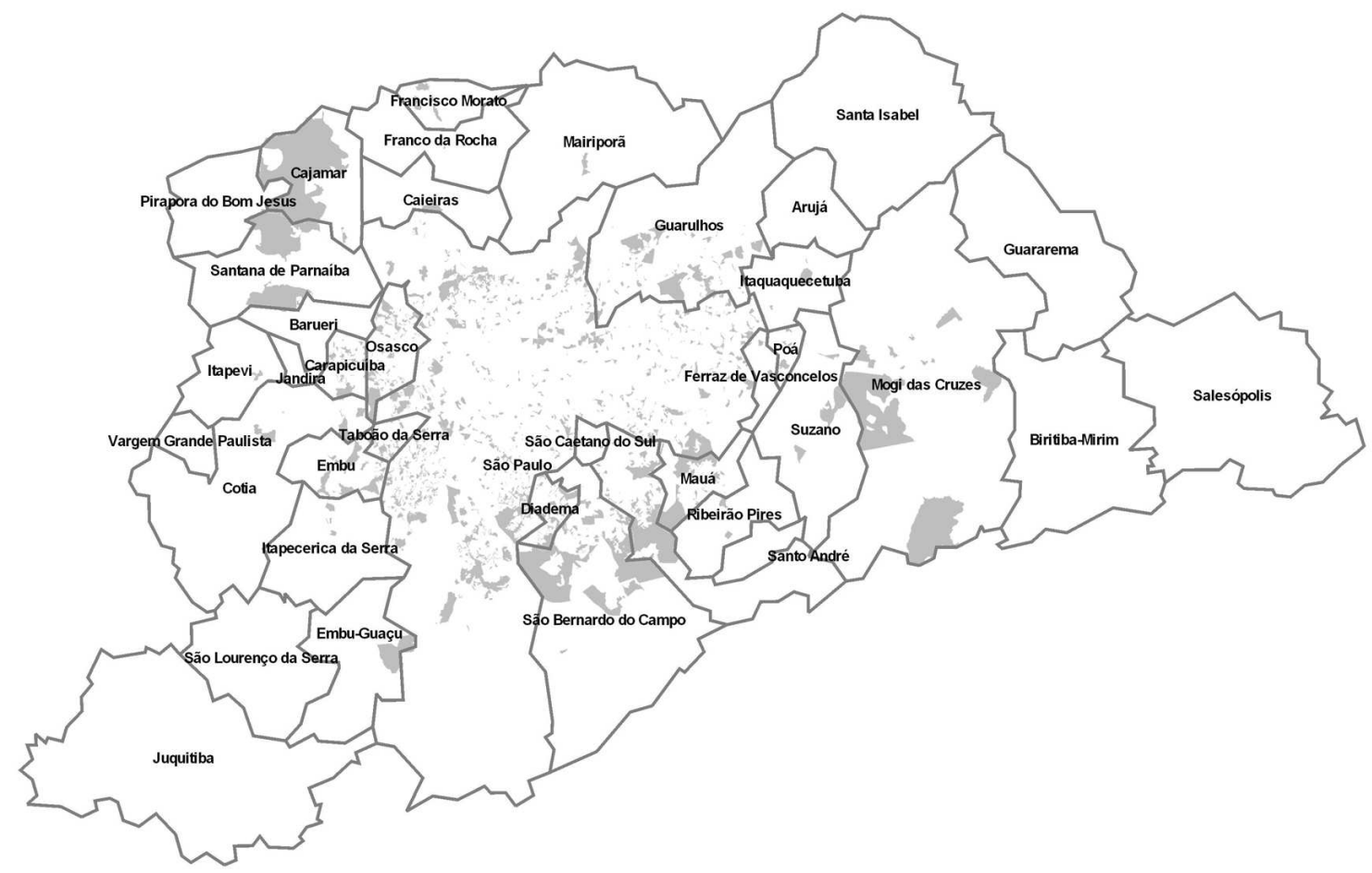

Fonte: LUME/FAUUSP

nômicas que esses eixos proporcionam - como comércio de beira de estrada, empresas de logística de transporte, acesso ao centro e outras cidades, acesso a condomínios residenciais de classe média, loteamentos fechados, concentração de polos de desenvolvimento com zonas industriais e ou de produção-podem ser apontados como fatores relevantes para a atratividade desses assentamentos nas cidades entrecortadas por essas rodovias.

Outro elemento que determina a concentração de favelas são as áreas de manancial e de proteção ambientais, caracterizadas pelo baixo valor imobiliário dos terrenos devido às restrições de uso impostas pela legislação ambiental.

\section{As favelas o espaço informal das cidades}

Por volta dos anos 30 , a cidade clandestina era duas vezes maior que a cidade oficial, e a questão social urbana era tratada como caso de polícia. Incapaz de comprar um terreno ou uma casa, ou ainda sem condições para locar um imóvel, a po- pulação de excluídos se viu obrigada a morar à margem da legislação em vigor, ou seja, na ilegalidade.

Vistas como sinônimo do caos urbano, as favelas fazem parte da malha urbana da cidade contemporânea, avizinhando-se, muitas vezes, da cidade legal. No entanto, ao contrário do que supõe a grande maioria, as favelas representam "um microcosmo onde se espelha o conjunto de situações socioeconômicas e culturais que caracterizam os habitantes pobres da cidade" (Kowarick 1979, p.159).

Ao reconhecer a existência das favelas e de espaços irregulares na cidade e propondo sua urbanização ou requalificação, transformado-as gradualmente em bairros, Estado e sociedade reconhecem a cidade real e criam condições de convivência entre aquilo que é tido como irregular - o espaço real - e a cidade legal. Porém é necessário que haja regras claras, para que o reconhecimento da cidade real não acabe expulsando as famílias mais carentes, como sempre acontece, dando continuidade ao circulo vicioso dessa expansão urbana desordenada. 


\section{Condomínios horizontais fechados na RMSP}

Em São Paulo, nos últimos vinte anos, os condomínios e loteamentos fechados ${ }^{6}$ constituem um fenômeno urbano cada vez mais presente, assim como em outras metrópoles brasileiras e mesmo latino-americanas.

Ao circularmos por algumas áreas da cidade de São Paulo, e mesmo em outras cidades da região metropolitana, podemos observar um número crescente de condomínios fechados existentes ou em construção. Ou, então, se prestarmos atenção às propagandas com lançamentos imobiliários entregues nos semáforos, podemos verificar um aumento na oferta dessa tipologia residencial.

O que hoje conhecemos como condomínios fechados na Região Metropolitana de São Paulo (e no Brasil, de um modo geral) eram originalmente grandes loteamentos fechados (como é o caso de Alphaville, lançado em Barueri nos anos 1970), localizados em grandes glebas vazias na periferia metropolitana e destinados exclusivamente às classes altas. A partir dos anos 1970, vários loteamentos fechados foram implantados em áreas periféricas da região metropolitana, em municípios como Barueri, Santana doParnaíbaeCotia, gerando novas áreas de expansão da cidade e da região, principalmente nos eixos Oeste e Sul, regiões antes pobres ou despovoadas.

A partir do início dos anos 1990, surgem os condomínios horizontais fechados propriamente ditos na Região Metropolitana de São Paulo. Um aumento gradual dos lançamentos desse novo tipo residencial vem ocorrendo desde então, principalmente nos últimos sete anos. No caso específico do município de São Paulo, a "Lei de Vilas", 7 de

${ }^{6}$ Os loteamentos fechados são parcelamentos comuns de lotes, com cercas ou muros que impedem a circulação pública nessas áreas. Já os condomínios fechados são parcelamentos fechados que incluem a construção das residências e de outros edifícios coletivos na sua implantação. As vias e áreas comuns dos loteamentos fechados são, na verdade, públicas. Já as vias e áreas coletivas dos condomínios são realmente privadas e de uso coletivo exclusivo dos condôminos (como acontece em um condomínio vertical). Segundo Blakely e Snyder (1995, p.2), condomínios são "áreas residenciais com acesso restrito, onde os espaços públicos são normalmente privatizados."

${ }^{7}$ Lei $n^{0} 11.605$ de 12 de julho de 1994. "Art $1^{\circ}$ Parágrafo único - O conjunto residencial horizontal do tipo R3-03 é aquele constituído por unidades habitacionais isola-
1994, possibilitou a instalação indiscriminada de pequenos condomínios horizontais (no estilo das antigas "vilas") em todas as zonas de uso residencial da cidade.

Além do aumento na oferta desse novo tipo de moradia, podemos observar também uma mudança na tipologia das unidades residenciais. Inicialmente implantados em grandes glebas, com unidades residenciais de alto padrão (com pelo menos três dormitórios e dois banheiros), vastas porções de áreas livres e de lazer de uso coletivo, atualmente, os novos condomínios fechados localizam-se, em geral, em áreas menores, mais centrais, com unidades residenciais menores, menos serviços e com áreas coletivas reduzidas.

Para Pasternak e Bógus (2003), naquele momento, o fator segurança de morar numa área murada e protegida não era o único determinante: ${ }^{8}$

... conforto de residir num local onde várias funções eram atendidas sem a necessidade de percorrer grandes distancias e, portanto, sem problemas de transporte. Aos poucos, essa solução residencial espalhou-se por outras áreas da cidade, tornando-se os condomínios verticais uma solução de moradia também para a população de alta renda que, com o aumento da violência urbana, passou a procurar novas formas de morar com conforto e segurança em áreas sofisticadas da cidade (p.64).

Caldeira (2000) procura debater a importância da proliferação desses enclaves fortificados na configuração urbana das cidades brasileiras, especialmente na RMSP:

Sobrepostas ao padrão centro-periferia, as transformações recentes estão gerando espaços nos quais os diferentes grupos sociais estão muitas vezes próximos, mas estão separados por muros e tecnologias de segurança, e tendem a não circular ou interagir em áreas comuns. O principal instrumento desse novo padrão de segregação espacial é o que chamo de 'enclaves fortificados', Trata-se de espaços privatizados, fechados e monitorados para residência, consumo, lazer e trabalho. A sua principal justificação é o medo do crime violento. Esses novos espaços atraem

das, agrupadas, geminadas ou superpostas, em condomínio, sendo nas zonas de uso que admitam o uso residencial./Art. $2^{\circ} \mathrm{O}$ conjunto residencial horizontal do tipo R3-03 somente poderá ser implantado em lotes ou glebas com área igual ou inferior a $15.000 \mathrm{~m}^{2}$."

${ }^{8} \mathrm{O}$ texto se refere à implantação do condomínio residencial vertical Ilhas do Sul no Alto de Pinheiros, em 1973. 
aqueles que estão abandonando a esfera pública tradicional das ruas para os pobres, os ' marginalizados' e os sem-teto (p.211).

O modelo de Cidade Dual delineado por Castells e Mollenkopf (1992), em que a estrutura social aproxima-se do formato de uma ampulheta, com mais ricos e pobres e praticamente sem classe média, nos leva a supor que o aumento das desigualdades e da exclusão social no contexto latinoamericano vem impulsionando a intensificação da segregação espacial.

Para entendermos parte da configuração da segregação espacial na Região Metropolitana paulistana, analisaremos os dados referentes aos lançamentos imobiliários realizados a partir de 1985, sistematizados pela Empresa Brasileira de Estudos de Patrimônio (Embraesp). ${ }^{9}$

A partir desses dados, elaboramos um quadro quantitativo e qualitativo dos condomínios horizontais fechados metropolitanos, a partir do qual é possível verificar a pertinência da discussão sobre a proliferação dos condomínios horizontais fechados no atual contexto urbano da metrópole paulistana.

O primeiro dado importante é que, apesar de a base de dados ter início no ano de 1985, apenas a partir de 1992 encontramos lançamentos de condomínios horizontais fechados. O modelo existente até então era o de loteamentos fechados a posteriori.

Conforme podemos observar na Tabela 4, no início, em 1992, os condomínios horizontais representavam apenas $2 \%$ do total de lançamentos residenciais na RMSP. Em 1999, sete anos depois, essa porcentagem alcança 14\% do total, atingindo um quarto dos lançamentos residenciais em 2001 ealcançando 35\% em 2004. Podemos verificar que o número de condomínios horizontais tem tido um aumento muito importante, principalmente nos últimos cinco anos, chegando, em 2004, a mais de um terço do total dos lançamentos imobiliários residenciais.

A partir da análise do Mapa 2 a seguir, pode-

${ }^{9}$ A Embraesp mantém um arquivo com dados sobre todos os lançamentos imobiliários da Região Metropolitana de São Paulo desde o ano de 1985. Todos os dados utilizados neste artigo fazem parte do banco de dados da Embraesp e foram cedidos para o desenvolvimento da pesquisa.

\begin{tabular}{|c|c|c|c|c|}
\hline \multirow[t]{2}{*}{ Ano } & \multicolumn{2}{|c|}{ Vertical } & \multicolumn{2}{|c|}{ Horizontal } \\
\hline & Lançamentos & $\%$ & Lançamentos & $\%$ \\
\hline 1985 & 367 & 100 & 0 & 0 \\
\hline 1986 & 746 & 100 & 0 & 0 \\
\hline 1987 & 276 & 100 & 0 & 0 \\
\hline 1988 & 342 & 100 & 0 & 0 \\
\hline 1989 & 454 & 100 & 0 & 0 \\
\hline 1990 & 288 & 100 & 0 & 0 \\
\hline 1991 & 216 & 100 & 0 & 0 \\
\hline 1992 & 209 & 98 & 4 & 2 \\
\hline 1993 & 415 & 96 & 17 & 4 \\
\hline 1994 & 523 & 98 & 12 & 2 \\
\hline 1995 & 547 & 95 & 30 & 5 \\
\hline 1996 & 532 & 93 & 41 & 7 \\
\hline 1997 & 520 & 94 & 34 & 6 \\
\hline 1998 & 375 & 93 & 28 & 7 \\
\hline 1999 & 343 & 86 & 54 & 14 \\
\hline 2000 & 470 & 83 & 95 & 17 \\
\hline 2001 & 393 & 75 & 128 & 25 \\
\hline 2002 & 435 & 71 & 174 & 29 \\
\hline 2003 & 485 & 71 & 201 & 29 \\
\hline 2004 & 433 & 65 & 236 & 35 \\
\hline
\end{tabular}

Fonte : Embraesp. Relatórios 1985-2004.

mos verificar que, de um total de 1.053 condomínios fechados, 859 (82\%) lançamentos foram feitos na cidade de São Paulo, sendo que apenas 194 (18\%) foram lançados em outros municípios da RMSP. Portanto, os condomínios fechados ainda são um modo de moradia bastante concentrado do município-polo ( $82 \%$ do total). Porém, se considerarmos a proporção desse tipo de moradia em relação ao total de domicílios, os condomínios fechados representam apenas $0,49 \%$ do total no município de São Paulo. Vários dos municípios da Região Metropolitana (principalmente a Leste e Sudoeste) não possuem nenhum lançamento desse tipo.

Quando observamos os municípios isoladamente, destacam-se Cotia, com 8,43\% das unidades em condomínio fechado, Barueri com 2,72\%, Poá com 1,59\%, São Bernardo do Campo com 1,48\% e São Caetano, Guarulhos, Mairiporã e Vargem Grande Paulista com cerca de 1\% do total das unidades residenciais em condomínios fechados.

\footnotetext{
${ }^{10}$ Os dados utilizados dizem respeito aos lançamentos anuais. Apesar do fato de que nem todos os condomínios lançados tenham sido necessariamente construídos, acreditamos que essa análise comparativa geral nos au-
} xilia no entendimento da realidade habitacional da RMSP. 


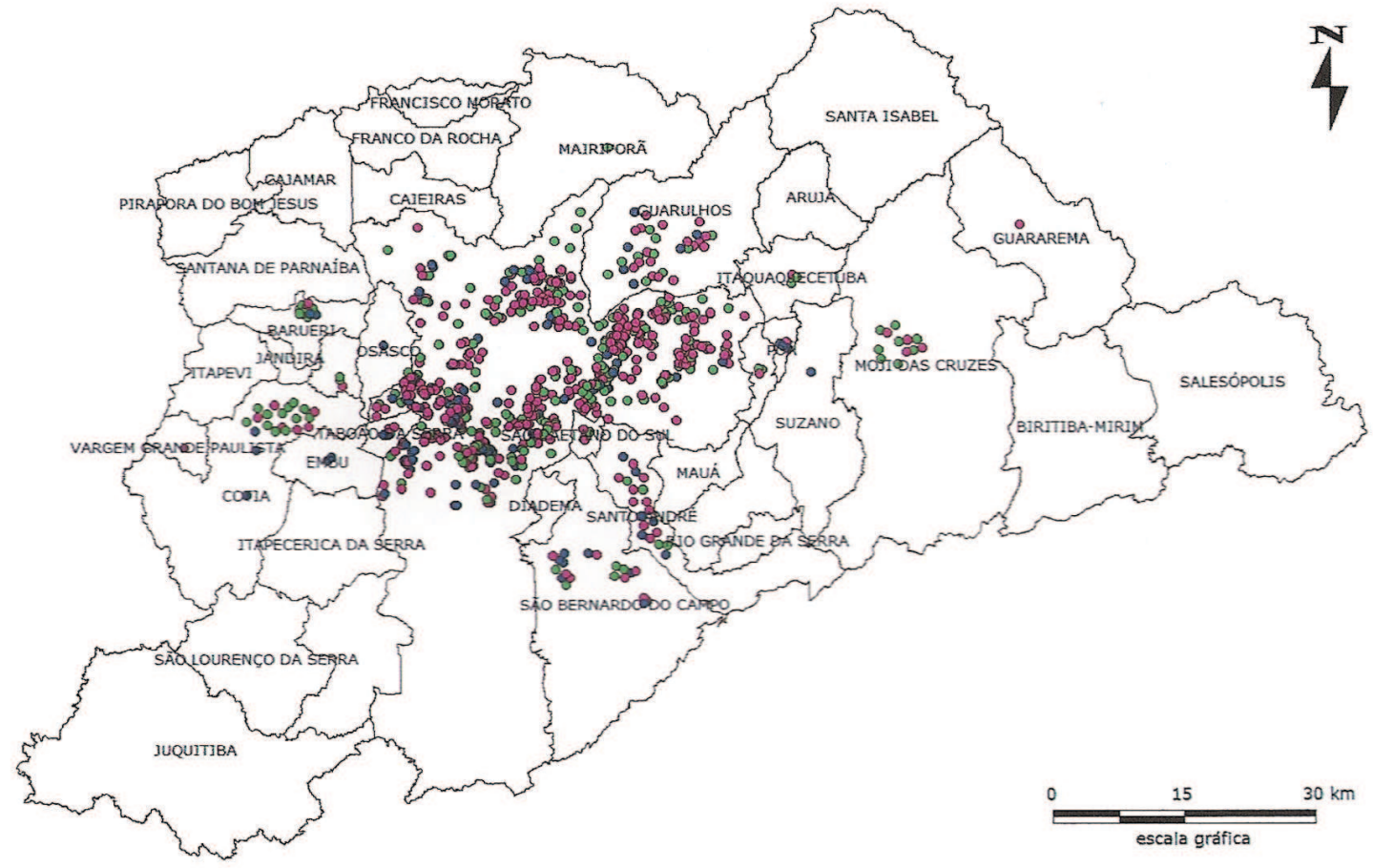

Fonte: Embraesp. Relatórios 1992 -2004

Os municípios de Cotia e Barueri fazem parte do eixo de expansão periférica dos grandes loteamentos fechados dos anos 1970 e 1980. No entanto, éinteressante observar, principalmente em Cotia, a importância que os bairros residenciais fechados continuam a ter no parque residencial municipal.

A concentração dos condomínios fechados está associada também à existência de estradas e avenidas que deem acesso rápido ao município-polo.

Ao analisarmos a tipologia residencial desses condomínios, encontramos características interessantes. Nas Tabelas 5 e 6, podemos observar o número de dormitórios e banheiros existentes nos 1.053 condomínios horizontais estudados. Alguns

Tabela 5 - Número de banheiros nas unidades residenciais

\begin{tabular}{c|c|c}
\multicolumn{2}{c}{$(\mathbf{1 9 9 2 - 2 0 0 4 )}$} & Total \\
\hline $\mathrm{N}^{\mathrm{o}}$ Banheiros & $\begin{array}{c}\text { Empreendimentos } \\
\text { End }\end{array}$ & 34,76 \\
\hline 1 & 366 & 40,08 \\
\hline 2 & 422 & 13,01 \\
\hline 3 & 137 & 12,16 \\
\hline
\end{tabular}

Fonte: Embraesp. Relatórios 1992-2004 dados são curiosos: cerca de 35\% das unidades lançadas têm apenas um banheiro, e 39\% tem entre um e dois dormitórios. A partir desse dado, poderíamos afirmar que a associação de condomínios fechados com unidades residenciais amplas e de alto padrão parece não ser sempre pertinente.

Como outro dado para análise, classificamos os condomínios em grupos, segundo a área útil total das unidades residenciais. Criamos quatro grupos: baixo padrão (com unidades de área útil total entre 35,00 e 74,99 m²); médio (entre 75,00 e 149,99 $\mathrm{m}^{2}$ ); alto (entre 150,00 e 299,99 $\mathrm{m}^{2}$ ); e altíssimo (unidades com área útil superior a 300,00 $\mathrm{m}^{2}$ ). O Gráfico 1 mostra a distribuição das unida-

Tabela 6 - Número de dormitórios nas unidades residenciais (1992-2004)

\begin{tabular}{c|c|c}
\hline$N^{\circ}$ Dormitórios & Total Lançamentos & $\%$ \\
\hline 1 & 3 & 0,28 \\
\hline 2 & 405 & 38,46 \\
\hline 3 & 414 & 39,32 \\
\hline 4 & 230 & 21,84 \\
\hline 5 & 1 & 0,09 \\
\hline
\end{tabular}

Fonte: Embraesp. Relatórios 1992-2004 
Gráfico 1- Lançamentos de condomínios horizontais por área útil (1992-2004)

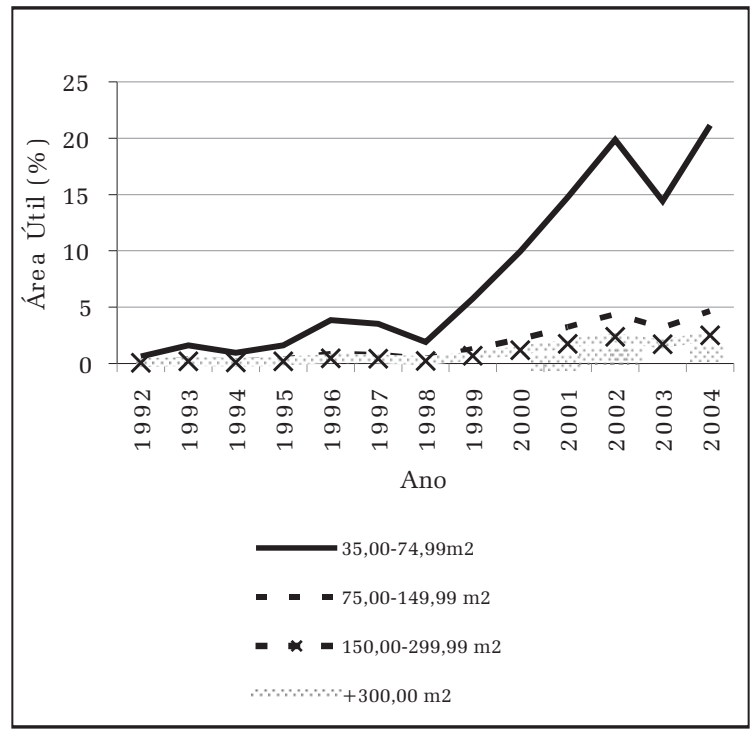

Fonte: Embraesp. Relatórios 1992-2004

des a partir dos grupos estabelecidos.

O maior número de lançamentos no período entre 1992 e 2004 é constituído de unidades residenciais com até $75,00 \mathrm{~m}^{2}$, o mesmo padrão de algumas unidades habitacionais populares fi- nanciadas pelo governo do estado. Em um condomínio lançado em Suzano, em 1993, as unidades possuíam um dormitório e um banheiro, com apenas $35,00 \mathrm{~m}^{2}$ de área útil, menor que muitas unidades da Cohab (Companhias de Habitação Municipais) ou CDHU (Companhia de Desenvolvimento Habitacional e Urbano do Estado de São Paulo).

O Mapas 3, 4, 5 e 6 mostram, no sentido horário, os condomínios na RMSP a partir das áreas úteis de suas unidades.

Os dois mapas superiores mostram os lançamentos com áreas úteis -menores, respectivamente, entre 35,00 e $74,99 \mathrm{~m}^{2}$ (esquerdo) e área útil entre 75,00 e $149,99 \mathrm{~m}^{2}$ (direito). Podemos notar uma grande concentração de lançamentos na zona Leste do município de São Paulo, região majoritariamente de baixa renda. O bairro de Ermelino Matarazzo, por exemplo, concentra vinte e dois lançamentos, enquanto, em todo o município de São Bernardo do Campo, foram lançados apenas 20 condomínios fechados.

Já os mapas inferiores mostram os lançamentos com áreas úteis maiores, com 150,00 a

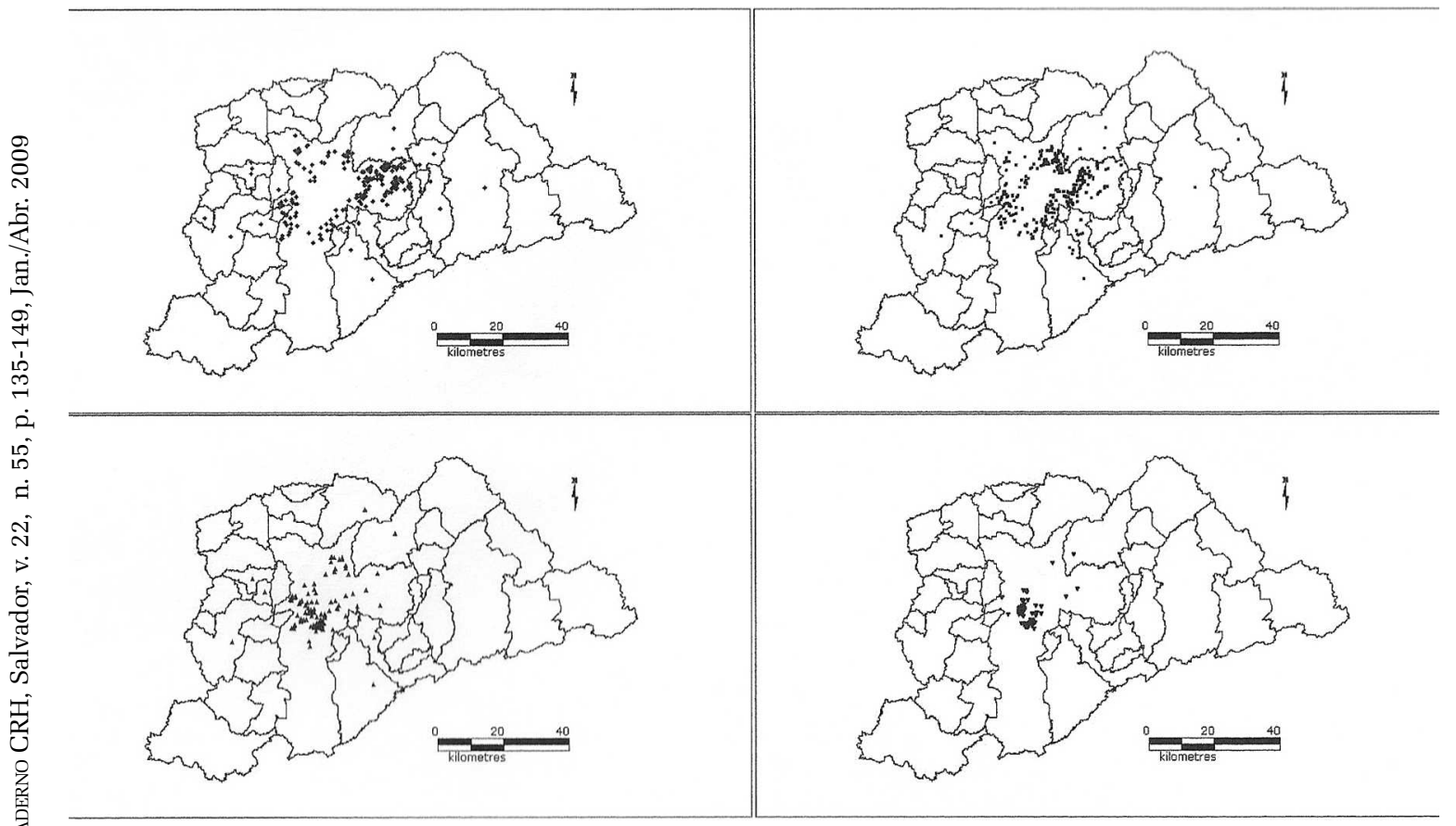

Fonte: Embraesp. Relatórios1992-2004 
Nelson Baltrusis, Maria Camila Loffredo D’Ottaviano

Tabela 7 - Lançamentos. Total de Unidades

\begin{tabular}{l|c|c|c|c|c|c}
\hline \multirow{2}{*}{ Total de Unidades } & \multicolumn{2}{|c|}{ RMSP } & \multicolumn{2}{c}{ Sáo Paulo } & \multicolumn{2}{c}{ Demais Municípios } \\
\cline { 2 - 7 } & Empreendimento & $\%$ & Empreendimento & $\%$ & Empreendimento & $\%$ \\
\hline até 10 & 540 & 47,4 & 522 & 55,0 & 18 \\
\hline de 11 a 20 & 286 & 25,1 & 256 & 27,0 & 31 \\
\hline de 21 a 50 & 171 & 15,0 & 119 & 12,5 & 25 & 16,2 \\
\hline de 51 a 100 & 87 & 7,6 & 39 & 4,1 & 48 & 27,2 \\
\hline mais de 100 & 56 & 4,9 & 13 & 1,4 & 42 & 22,0 \\
\hline
\end{tabular}

Fonte: Embraesp. Relatórios 1992-2004

299,99m² (esquerdo) eárea útil superior a 300,00m² (direito), onde podemos observar uma realidade mais próxima da esperada: a grande concentração de alto e altíssimo padrão principalmente na zona Sudoeste da capital. Encontramos, porém, alguns lançamentos de alto padrão também na zona Leste (dois) e na zona Norte da cidade de São Paulo (um) e outro em Guarulhos.

A Tabela 7 mostra os lançamentos em função do número total de unidades residenciais. Praticamente metade dos lançamentos $(47,4 \%)$ possui no máximo 10 unidades. Um quarto do total $(25,1 \%)$ possui entre 10 e 20 unidades. Ou seja, a grande parte dos lançamentos (72,5\%) são condomínios não muito grandes, como no máximo 20 unidades residenciais.

Se considerarmos apenas os lançamentos na capital, $82 \%$ do total possuem até no máximo 20 unidades. A proporção praticamente se inverte se considerarmos apenas os lançamentos nos demais municípios da região metropolitana: 74,3\% dos lançamentos possuem 21 ou mais unidades.

A Tabela 8 mostra os lançamentos em função do tamanho total da gleba. Grande parte dos lançamentos (42\%) situa-se em terrenos com até $1.000,00 \mathrm{~m}^{2}$. Esse é um padrão de lote urbano encontrado em vários dos bairros paulistanos e metropolitanos. Se considerarmos lotes de até

Tabela 8 - Tamanho da Gleba

\begin{tabular}{l|c|c}
\hline Tamanho dos Lotes (m2) & Empreendimento & \% \\
\hline até 500 & 199 & 17,5 \\
\hline $500-1.000$ & 280 & 24,6 \\
\hline $1.000-2.000$ & 250 & 21,9 \\
\hline $2.000-5.000$ & 223 & 19,6 \\
\hline $5.000-10.000$ & 114 & 10,0 \\
\hline + de 10.000 & 74 & 6,5 \\
\hline
\end{tabular}

Fonte: Embraesp. Relatórios 1992-2004
$5.000,00 \mathrm{~m}^{2}$, esse total sobe para $83,6 \%$ de todos os lançamentos. Ou seja, a maioria absoluta dos condomínios horizontais da Região Metropolitana de São Paulo está sendo lançada em lotes com no máximo 5.000,00m².

Dos empreendimentos que possuem entre 51 e 100 unidades, apenas 34,5\% (30) foram lançados no município de São Paulo. Se considerarmos os empreendimentos com mais de 100 unidades, esse percentual cai para 17,8\% (10) do total.

Já os empreendimentos lançados em glebas com área superior a $10.000 \mathrm{~m}^{2}$, apenas $28 \%$ (21) localizam-se no município de São Paulo.

Como o município de São Paulo concentra a maior parte dos lançamentos (83\%), esses são dados significativos. Indicam que os condomínios horizontais de maiores dimensões estão, de fato, sendo lançados, sobretudo, fora da capital.

A leitura dos Mapas, Tabelas e do Gráfico possibilita a compreensão de um quadro sucinto, porém com questões importantes em relação à realidade dos condomínios fechados na Região Metropolitana de São Paulo.

De um modo geral, constata-se o aumento da oferta desse tipo de moradia quando observamos os mapas temáticos. No entanto, questões como a localização e a tipologia das habitações não correspondem à ideia preconcebida em relação aos condomínios fechados: os condomínios estão muito concentrados no município de São Paulo e não espalhados em toda a periferia metropolitana; uma parcela considerável dos lançamentos tem áreas úteis pouco superiores às de uma unidade popular da Cohab; e os condomínios fechados também se localizam em áreas de baixa renda da cidade. 


\section{AS NOVAS FORMAS DE APROPRIAÇÃO DO ESPAÇOURBANO}

O processo de urbanização das cidades brasileiras, nos últimos 50 anos, consolidou um padrão de ocupação do solo caracterizado pela desigualdade socioespacial, reflexo das desigualdades socioeconômicas. Se as favelas existem na cidade de São Paulo desde o início do século passado, a sua inserção comoum problema de moradia para a baixa renda se consolida nos anos 80, como destacam vários autores (Kowarick, 1979; Singer, 1979; Pasternak, 1997 entre outros). Até a década de 1970, a principal forma de acesso à moradia pelos pobres se dava pelo "padrão periférico de expansão urbana”, ou seja, através da proliferação de loteamentos irregulares e (ou) clandestinos, em áreas periféricas não urbanizadas. A consolidação de assentamentos informais, a partir dos anos 80, reflete as condições socioeconômicas do período - desemprego, falta de política habitacional e o processo de redemocratização do país. A incapacidade do poder público instituído em dar respostas à demanda da população fez com que a população organizada ocupasse, para fins de moradia, glebas públicas e privadas. Muitas dessas ocupações se transformaram em favelas.

A partir da década de 1980, as favelas consolidadas ganharam um novo padrão de qualidade urbana: os programas de reurbanização. Esses programas, implantados em geral pelo poder local, permitiram que tanto as favelas como os loteamentos precários em áreas periféricas pudessem ter acesso aos serviços públicos básicos e bens de consumo. Os recentes programas de regularização fundiária têm possibilitado a permanência dos moradores nos assentamentos ilegais que não ofereçam riscos de vida ou ambientais, prevalecendo a doutrina da posse segura. Essas intervenções capitaneadas pelo poder público produziram a melhoria das condições geral de habitabilidade. No entanto, os problemas do crescimento do número de favelas e de população favelada só tornam a questão da moradia mais complexa. Até quando será possível intervir? Não seria melhor adotar políticas de acesso à moradia que beneficiassem a população mais pobre? Vale destacar ainda que, atualmente, o espaço favelado se mercantilizou. Baltrusis (2005) destaca que a principal forma de acesso a uma favela, no contexto atual, se faz através do mercado imobiliário informal, tanto em transações de compra e venda, como através da locação. Existem estruturas dentro das favelas para produzir, comercializar e locar os bens imobiliários. Isso só foi possível diante a incapacidade de gestão do poder público para produzir novas unidades habitacionais e também para compreender essa forma de ocupação e criar instrumentos para gerir essa nova realidade.

Não deixa de chamar a atenção o fato de que, ao mesmo tempo em que a população de baixa renda se movimentava para ocupar o vazio institucional, transformando os vazios urbanos em assentamentos e expondo territorialmente as desigualdades socioeconômicas da população, podemos observar um grande aumento no número de condomínios fechados na Região Metropolitana de São Paulo, o que, nos últimos quinze anos, veem modificando a configuração espacial de algumas áreas dessa Região.

A partir da apresentação do quadro dos condomínios horizontais na Região Metropolitana de São Paulo, levantamos alguns questionamentos relativos às premissas da configuração do espaço urbano metropolitano.

Primeiramente, quando verificamos a existência de unidades habitacionais com trinta e cinco, cinquenta ou mesmo setenta e cinco metros quadrados de área útil, não podemos imaginar que essas sejam moradias das classes altas metropolitanas. A partir do mapeamento realizado, não mais podemos associar os condomínios fechados como forma de morar exclusiva da elite (entendida como classes de alta renda).

Em relação às motivações para a escolha desse tipo de moradia, se a segurança é o principal motivo para essa escolha, outra questão deve ser colocada: será que os moradores dos condomínios onde as unidades habitacionais têm trinta ecinco ou cinquenta metros quadrados possuem renda suficiente para 
pagar o aparato de segurança normalmente utilizado nos condomínios fechados (seguranças, guaritas, câmeras, cercas elétricas, alarmes, etc.)?

A última ponderação diz respeito aos pressupostos teórico-analíticos da segregação socioespacial e indica uma tendência de superação do modelo centro-periferia por um modelo fractal de segregação espacial nas metrópoles contemporâneas.

Quando observamos a existência de um grande número de condomínios horizontais fechados na zona Leste do município de São Paulo, por exemplo, o modelo da cidade dual apontada por Castells e Mollenkopf (1992) parece claro. Mesmo entre a população mais pobre, os grupos de melhor condição financeira se destacam do todo.

Analisando a totalidade dos lançamentos de condomínios horizontais na RMSP, ainda podemos identificar uma centralidade em relação à localização dos condomínios fechados, principalmente os de alto e altíssimo padrão. Isso nos faz pensar que talvez o que tenha mudado seja não o modelo centro-periferia, mas precisamente o que entendemos por centro e por periferia na metrópole contemporânea.

Podemos encontrar vários exemplos do modelo fractal no contexto urbano da Região Metropolitana, porém devemos analisar se essa é a regra geral ou representa apenas exemplos pontuais, como o da favela de Paraisópolis, Ermelino Matarazzo ou Alphaville.

Acreditamos que devemos entender o centro não apenas como a área central da cidade de São Paulo (a região do centro expandido, entre as marginais dos rios Pinheiros e Tietê), mas sim como toda a cidade de São Paulo (com exceção do extremo sul). A periferia metropolitana nãoé mais toda a área localizada para além marginais, mas sim a área para além dos limites municipais. Ou seja, devemos entender a centralidade no seu contexto metropolitano.

Os condomínios horizontais fechados da Região Metropolitana de São Paulo representam, sem dúvida alguma, um padrão de exclusão social e segregação espacial. Porém sua distribuição espacial na metrópole não pode ser considerada apenas como consequência do padrão fractal de se- gregação espacial. E, sobretudo, não podemos mais associar automaticamente os condomínios fechados à residência exclusiva das classes altas metropolitanas. O novo quadro apresentado parece sugerir que devemos estabelecer novos padrões de análise desse fenômeno urbano que se consolidou nas últimas duas décadas.

(Recebido para publicação em janeiro de 2008) (Aceito em novembro de 2008)

\section{REFERÊNCIAS}

ABRAMO, P. Teoria econômica da favela. Quatro notas sobre a localização residencial e o mercado imobiliário informal. In: _. (Org.) A cidade da informalidade. O desafio das cidades latino-americanas. Rio de Janeiro: Sette Letras/FAPERJ/Lincoln Institute of Land Policy, 2003.

BALTRUSIS, N. A dinâmica do mercado imobiliário informal nas favelas de Paraisópolis e Nova Conquista. 2000. Dissertação (Mestrado em Urbanismo) Pontifícia Universidade Católica de Campinas, 2000.

O mercado imobiliário informal em favelas e o processo de estruturação das cidades. 2005. Tese (Doutorado em Arquitetura e Urbanismo) - Programa de Pósgraduação em Arquitetura e Urbanismo da Universidade de São Paulo, 2005

BONDUKI, N. G.; ROLNIK, R. Periferia da Grande Sao Paulo. In: MARICATO, E. "A Produção Capitalista da Casa e da Cidade no Brasil Industrial.” ED. Alfa-Omega. São Paulo, 1979

BLAKELY, E; SNYDER, M. Fortress America. Gated Communities in the United States. Harrisonburg: Brookings Institution \& Lincoln Institute of Land Police, 1995.

CALDEIRA, T. Cidade de muros: crime, segregação e cidadania em São Paulo. São Paulo: Edusp/Editora 34, 2000.

CASTELLS, Manuel.; MOLLENKOPF, J. Dual city. Restructuring New York. Nova York: Russel Sage Foundation, 1992.

DAVIS, M. Planeta favela. São Paulo: Boitempo Editorial, 2006

DENALDI, Rosana. Favelas no grande $A B C$ : crescimento e balanço das intervenções. Santo André,SP: UniABC 2000. Resultados de pesquisa desenvolvida pela FAU UniABC

D’OTTAVIANO, M.C.L. Condomínios fechados na Região Metropolitana de São Paulo: fim do modelo centro rico versus periferia pobre? 2008. Tese (Doutorado em Arquitetura e Urbanismo) - Faculdade de Arquitetura e Urbanismo da Universidade de São Paulo, 2008.

EMPRESA BRASILEIRA DE ESTUDOS DE PATRIMÔNIO(EMBRAESP) Relatórios anuais 1985-2005. São Paulo.

HARVEY, David. Condição pós-Moderna: Uma Pesquisa sobre as Origens da Mudança Cultural. São Paulo: Edições Loyola, 2002.

KOWARICK, Lúcio. A espoliação urbana. Rio de Janeiro: Paz e Terra, 1979. 
MARICATO, E. "A Produção Capitalista da Casa e da Cidade no Brasil Industrial” ED. Alfa-Omega. São Paulo. 1979

MARICATO, Ermínia. Brasil, cidades alternativas para a crise urbana. Petrópolis: Vozes, 2001

PASTERNAK, Suzana. A favela que virou cidade. In URBAN RESEARCH SYMPOSIUM, 2005, Brasília. Anais...[S.l.], 2005. p. 1-33.

O Brasil e suas favelas. In: ABRAMO, P. (Org.) A cidade da informalidade: o desafio das cidades latinoamericanas. Rio de Janeiro: Sette Letras/FAPERJ/Lincoln Institute of Land Policy, 2003.

Favelas e cortiços no Brasil: 20 anos de pesquisa e políticas. Cadernos de Pesquisa do LAP. São Paulo, FAU/ USP, n.18, 1997.

; BALTRUSIS, N. Um olhar sobre a habitação em São Paulo. Cadernos Metrópole. São Paulo, EDUC, n. 9 , 2003.

; BOGUS, L. A cidade dos anéis. Cadernos de Pesquisa do LAP. São Paulo, FAU/USP, n.28, 1998.

; BOGUS, Lucia M. M. A cidade dos extremos. Revista Cidades, Comunidades e Territórios. Lisboa, Fundação para a Ciência e a Tecnologia/ISCTE, n. 6, jun., p.51-72, 2003.
SINGER, P. "O Uso do solo Urbano na Economia Capitalista” in. MARICATO, E. "A Produção Capitalista da Casa e da Cidade no Brasil Industrial” ED. Alfa-Omega. São Paulo. 1979

SOUZA, M. O desafio metropolitano. Um estudo sobre a problemática sócio-espacial nas metrópoles brasileiras. Rio de Janeiro: Bertrand Russel, 2000.

SPOSATI, A. (coord.). Mapa da inclusão/exclusão social da cidade de São Paulo. São Paulo, Educ, 1996.

TORRES, H.G; MARQUES, E. Tamanho populacional das favelas paulistanas. Ou os grandes números e a falência do debate sobre as metrópoles. In: ENCONTRO DA ASSOCIAÇÃO BRASILEIRA DE ESTUDOS POPULACIONAIS, 18 , 2002, Ouro Preto, MG, Anais... São Paulo, ABEP, 2002.

VALLADARES, L.P.; PRETÉCEILLE, E. Favela, favelas: unidade ou diversidade da Favelas. In: QUEIROZ RIBEIRO, L.C. O futuro das metrópoles: desigualdades e governabilidade. Rio de Janeiro: Observatório IPPUR/UFRJFASE/Revan, 2000

VILLACA, Flávio. Espaco intra-urbano no Brasil. São Paulo: Studio Nobel/FAPESP/Lincoln Institute, 2001. 


\section{RICH AND POOR, EACH ONE IN THEIR PLACE: socioespatial inequality in São Paulo}

\author{
Nelson Baltrusis \\ Ottaviano Maria Camila Loffredo
}

The slums and the walled condominiums express the duality of rich and poor living in São Paulo metropolitan area. The occurrences of those settlements begin, in the case of slums, in the first half of the XX century, and, , in the case of the walled condominiums and developments, in the 1970's. This paper intends to analyze and to identify both the spaces of homes in condition of extreme vulnerability, particularly the slums and habitational units in precarious outlying neighborhoods, and the ways of structuring the space for living for the rich and the middle class, highlighting, preferentially, the walled horizontal condominiums, as real state forms that represent the two extremes of the current socioterritorial inequality in the urban and metropolitan context of São Paulo. We will also think about the new forms of space appropriation for rich and of poor living, trying to understand if there really is a new pattern of occupation of soil in the São Paulo Metropolitan Area.

KEYwORDs: slums; walled condominiums; socioespatial exclusion; São Paulo Metropolitan Region.
RICHESET PAUVRES, CHACUNASA PLACE: l' inégalite socio-spaciale dans la métropole de São Paulo

\author{
Nelson Baltrusis \\ Ottaviano Maria Camila Loffredo
}

Les favelas et les copropriétés en régime fermé démontrent la dualité des types d'habitation des riches et des pauvres dans la métropole de Sao Paulo. L'avènement de ce genre de regroupement d'habitations existe depuis la première moitié du XXe siècle en ce qui concerne les favelas et à partir des années 70 pour les copropriétés fermées. Ce travail se veut d'analyser et d'identifier autant les espaces réservés aux maisons qui se trouvent dans des conditions extrêmement vulnérables, et tout particulièrement les favelas et les quartiers précaires situés dans les périphéries, que la structuration de l'espace réservé aux résidences des riches et de la classe moyenne. On met tout spécialement en évidence les copropriétés horizontales fermées, type d'habitations qui représentent les extrémités de l'inégalité socio territoriale existante dans le contexte urbain et métropolitain de Sao Paulo. Nous ferons aussi une réflexion sur les nouvelles manières de s'approprier l'espace pour l'habitation des riches et des pauvres, pour vérifier s'il existe vraiment une nouvelle norme d'occupation du sol dans la Région Métropolitaine de Sao Paulo.

Mots-CLÉs: favelas, copropriétés fermées, exclusion socio spatiale, RMSP.

Nelson Baltrusis - Doutor em Arquitetura e Urbanismo pela Faculdade de Arquitetura e Urbanismo da Universidade de São Paulo. Professor do programa de pós-graduação em planejamento territorial e desenvolvimento social da Universidade Católica do Salvador. Coordena e integra o Núcleo de Pesquisa Desenvolvimento Municipal e participa como pesquisador do Observatório das Metrópoles (núcleo Salvador) desenvolvendo pesquisas na área de planejamento urbano. Suas mais recentes publicações, são: VASCONCELOS, P. A.; BALTRUSIS, Nelson. Planning and Segregation. In: New concepts and approaches for urban and regional policy and planning? 2007, Louven. New concepts and approaches for urban and regional policy and planning?. Louven: ESDP / SP SP, 2007. p. 1-14; BALTRUSIS, Nelson . Os mistérios, os truques e os milagres do capital e o crescimento da informalidade urbana. In: Maria Lúcia Caira Gitahy; José Tavares Correia de Lira (Org.). Cidade: impasses e perspectivas (Arquiteses 2). São Paulo: Annablume, 2007.

Maria Camila Loffredo D’Ottaviano - Doutora em Arquitetura e Urbanismo e Mestre em Estruturas Ambientais Urbanas pela FAU-USP. Professora do Curso de Arquitetura da Universidade São Francisco (USF) Itatiba. Pesquisadora do Centro de Estudos Urbanos (CEUr) da USF. Coordenadora do Projeto Habitamparo de Regularização Fundiária. Integra o Núcleo de Pesquisa Observatório das Metrópoles São Paulo, desenvolvendo pesquisas na área de segregação sócio-espacial e residencial e irregularidade urbana. Suas mais recentes publicações são: Condomínios Fechados na Região Metropolitana de São Paulo: consolidação de um novo padrão de exclusão social e segregação espacial. In: Valença, M. Globalização e Marginalidade. Natal: EDUFRN, v. 1, 2008; Gated Communities in SPMA: a new pattern of urban segregation?. In: International Planning History Society 13th Biennial Conference, 2008, Chicago; Regularização Fundiária no Brasil: possibilidades abertas pelo Estatuto da Cidade. O caso Jaguary. In: Anais da XII ENANPUR, Florianópolis, 2009. 
